\title{
In-Rack Fire Plumes
}

\author{
HAUKUR INGASON \\ Swedish National Testing and Research Institute (SP) \\ Box 857, S-501 15 Borås, Sweden
}

\begin{abstract}
A theoretical and experimental study of in-rack fire plumes in a combustible rack storage is presented. The commodity used in the experiments consisted of multiple-wall corrugated paper cartons equally separated in a steel rack, two cartons wide, two cartons deep and four cartons high. Free-burn tests were carried out mostly in reduced scale with verification in full scale. The centreline in-rack gas temperatures and velocities were measured at four elevations inside the rack storage and the heat release rate was measured above the rack storage with a hood system. In-rack temperatures and velocities are plotted using theoretically obtained quasi-steady correlations assuming a point source of buoyancy at floor level and entrainment only in the vertical flues. The theoretical correlations include convective heat release rate, vertical flue width and height above the floor. Temperatures for both reduced scale and full scale correlate reasonably well with the theoretically obtained relationships which have the same functional form as convective plume flow above a linear fire source (line plume). In order to obtain similar correspondance for the velocity in the two scales it was necessary to use Froude number scaling with storage height as length scale.
\end{abstract}

The storage arrangement is found to be important for the initial flame spread and fire growth rate. The reduced scale study shows that the initial fire growth rate decreases with increasing vertical gaps (flues) and that the vertical and lateral flame spread rate increase when the lateral flue height increases. For the initial in-rack fire growth rate, the convective heat release rate was found to be better described by an exponential function rather than a power-law dependence on time to the third power.

KEYWORDS: rack storage fire, convective heat release rate, in-rack plume flow, in-rack temperature, in-rack velocity

\section{NOMENCLATURE}

$\begin{array}{ll}\mathrm{A} & \text { fire plume area }\left(\mathrm{m}^{2}\right) \\ \mathrm{C}_{\mathrm{p}} & \text { specific heat }(\mathrm{kJ} / \mathrm{kg} \mathrm{K}) \\ \mathrm{f} & \text { momentum flux }\left(\mathrm{kg} \mathrm{m} / \mathrm{s}^{2}\right) \\ \mathrm{g} & \text { gravitational acceleration }\left(\mathrm{m} / \mathrm{s}^{2}\right)\end{array}$

$\mathrm{t}_{0} \quad$ incipient time of fire growth (s)

$\mathrm{T}_{0} \quad$ ambient temperature $\left({ }^{\circ} \mathrm{C}\right)$

$\mathrm{T}$ in-rack temperature $\left({ }^{\circ} \mathrm{C}\right)$

$\Delta \mathrm{T} \quad$ temperature rise above ambient $\left({ }^{\circ} \mathrm{C}\right)$ 
$\Delta \mathrm{H}_{\mathrm{c}}$

\section{$\mathrm{H}$}

$\mathrm{h}$

m

Q

$\mathrm{Q}_{\mathrm{c}}$

$\mathrm{Q}_{\mathrm{c}, 0}$

$\mathrm{Q}_{\mathrm{c}, 0}$

$\Delta \mathrm{Q}_{\mathrm{c}}$

$\mathrm{t}$ heat of combustion $(\mathrm{kJ} / \mathrm{g})$

height of rack storage $(\mathrm{m})$

height of horizontal flue $(\mathrm{m})$

mass flux of air $(\mathrm{kg} / \mathrm{s})$

total heat release rate $(\mathrm{kW})$

convective heat release rate $(\mathrm{kW})$

the convective heat release rate at $t_{0}$

the convective heat release rate at $t_{0}$

net convective heat release rate; $Q_{c}-Q_{c, 0}$

time from ignition (s) $\mathrm{u} \quad$ in-rack velocity $(\mathrm{m} / \mathrm{s})$

$\mathrm{u}_{\mathrm{f}} \quad$ mean flame height speed $(\mathrm{m} / \mathrm{s})$

$\mathrm{w}$ width of the vertical flue (m)

$\mathrm{z}$ height from floor (m)

$\mathrm{z}_{0} \quad$ height of virtual origin (m)

$\alpha \quad$ entrainment coefficient

$\rho_{0} \quad$ ambient density $\left(\mathrm{kg} / \mathrm{m}^{3}\right)$

$\rho \quad$ density within a flue $\left(\mathrm{kg} / \mathrm{m}^{3}\right)$

$\tau \quad$ time constant (s)

\section{INTRODUCTION}

Fire growth rate and flame propagation are dependent on how the burning material is stored. In rack storage fires this becomes extremely important as the upward flame propagation is usually very rapid. The vertical shafts, or flues, created between adjacent pallets of stored goods tend to work as chimneys and enhance acceleration of flames up to the ceiling. Rack storage fire protection usually consists of in-rack sprinklers which are placed at different elevations in the vertical flues or on the faces of the rack storage. The efficiency of such protection depends on the geometry of the stored goods, their height, the flue dimensions and intervals of occurrence as well as the flammability of the stored goods. The delay prior to in-rack sprinkler actuation is extremely important as this may be critical for control of the fire. To calculate the response time, a knowledge of the flow conditions at the sprinkler is necessary. A theoretical model which can predict these flow conditions is therefore of interest.

Previous work [1,2] on in-rack plume flow in a two dimensional (2D) non-combustible rack storage indicates that the width of the vertical flue is the governing geometric parameter for the in-rack plume flow. Further, variation of the horizontal flue heights was found to have negligible effects on the in-rack plume flow. No consideration was given to the problem of heat transfer from the flame to the surrounding walls which is of importance for flame spread studies. Foley and Drysdale [3], however, recently published a thorough study of this problem where they used a similar configuration. They showed that as the separation between the walls is reduced the heat flux to the walls increases.

Thomas [4] studied some large scale fire test performed in the United Kingdom and found some evidence that the width of the vertical flue affects speed of flame spread. He suggested there is a gap size with a highest spread rate but clearly three dimensional features of the flow are involved too. A number of large scale tests have been carried out by various fire laboratories for the purpose of studying the behaviour of sprinkler systems in controlling rack storage fires [511]. Factory Mutual Research Corporation (FMRC) [5-7] carried out a great number of full scale sprinklered and free burning tests demonstrating the rapid spread of flames when different commodities are stored in racks. Previous theoretical work [5-7] on rack storage fires have been directed to predict what occurs above the rack storage rather than what occurs inside it. Yu and Stavrianidis [5] presented an empirical fire growth rate correlation as a power-law dependence on time to the third power for $2,3,4$ and 5 tier rack storage fires. The initial fire growth rate was found to be invariant with number of tiers. Variations or effects of different flue separations was not studied.

To date no systematic investigation of the influence of gap size on fire growth rate has been undertaken. A systematic variation in vertical and lateral gap sizes was carried out in the present study. Similarly no theoretical model has previously been available to predict the flow conditions in a three dimensional (3D) rack storage configuration. Such a model is presented and compared to the experimental results. 


\section{THEORETICAL ASPECTS}

An exploratory model for a non-reacting turbulent in-rack plume is outlined here. In rack storage fires, air is entrained into the in-rack fire plume mainly through vertical flues but also through horizontal flues. However, to be able to find a simple theoretical solution we assume in the first approximation that no air is entrained through the horizontal flues. Thus, the rack storage configuration can be simplified from figure 1 a) to the configuration shown in figures $1 b)$ and 1c). The following assumptions have been made:

- plume buoyancy stems from a point;

- the air entrainment velocity at the edge of the in-rack plume is proportional to the local vertical velocity, $u$;

- no air is assumed to be entrained through the horizontal flues;

- the shape of the in-rack plume cross-section is assumed to be the same at all heights, see figures $1 \mathrm{~b}$ ) and $1 \mathrm{c})$;

- $u$ and $\rho$ have top hat profiles; no horizontal pressure variation exists between the in-rack plume and the surrounding air;

- the ambient air is of uniform temperature;

- the flue gases have the same molecular weight as air;

- no heat losses occur to the surrounding walls; and

- the drag exerted by the cartons is neglected.

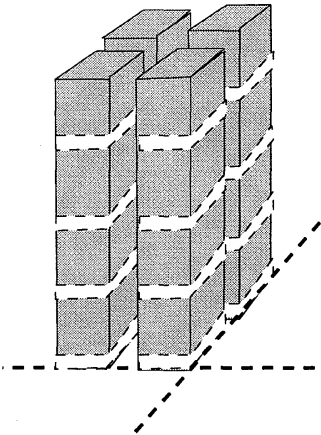

a)

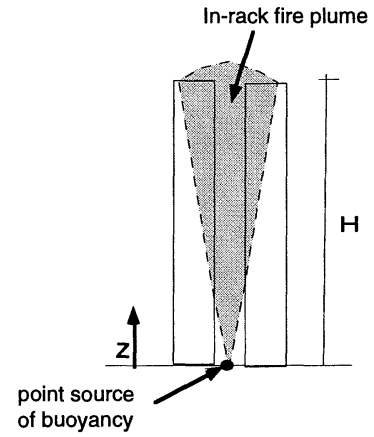

b)

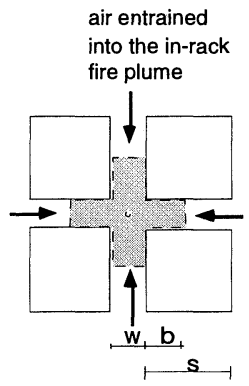

c)

FIGURE 1. a) Illustration of a $3 D$ rack storage b) side view of the simplified model c) birdseye view of the simplified model.

The equations for the conservation of continuity, momentum and energy are therefore: 
$\frac{d}{d z}(\rho u A)=\rho_{0} \alpha u 4 w$

$\frac{d}{d z}\left(\rho u^{2} A\right)=\left(\rho_{0}-\rho\right) g A$

$Q_{c}=\rho u A C_{p}\left(T-T_{0}\right)$

In these equations $z$ is the height above the floor, $A$ is the mean in-rack plume area, $\alpha$ is the entrainment coefficient at the edge of the in-rack plume, $w$ is the vertical flue width, $u$ is the mean in-rack velocity, $\rho$ is the mean in-rack density (essentially air), $C_{p}$ is the specific heat of the in-rack plume and $Q_{c}$ is the instantaneous convective heat release rate. An interesting observation is that these equations are similar to those for fires with a linear buoyancy source, see Lee and Emmons [12]. To solve eqns (1)-(3) we introduce the mass flux: $m=\rho u A$ and the momentum flux: $f=\rho u^{2} A$ as two new variables. Substituting these new variables into eqns (1)(3) yields:

$\frac{d m}{d z}=4 \alpha w \rho_{0} \frac{f}{m}$

$\frac{d f}{d z}=g \frac{\left(\rho_{0}-\rho\right)}{\rho} \frac{m^{2}}{f}$

$Q_{c}=m C_{p} T_{0} \frac{\left(\rho_{0}-\rho\right)}{\rho}$

Rearrangement and integration of these equations yields the desired relationship:

$m^{3}=\frac{4 \alpha \rho_{0} C_{p} T_{0}}{g} \frac{w}{Q_{c}} f^{3}+C$

In order to obtain a simplified functional relationship for further analysis the integration constant $\mathrm{C}$ has to be equal to zero. We substitute $m=\rho u A$ and $f=\rho u^{2} A$ into eqn (7) which gives the inrack velocity:

$u=\left(\frac{g}{4 \alpha \rho_{0} C_{p} T_{0}}\right)^{1 / 3}\left(\frac{Q_{c}}{w}\right)^{1 / 3}$

Integration of eqn (4) up to the height from the floor level, $z$, gives the mass flux as a function of height:

$m=\left(4 \alpha \rho_{0}\right)^{2 / 3}\left(\frac{g}{C_{p} T_{0}}\right)^{1 / 3}\left(w^{2} Q_{c}\right)^{1 / 3} z$ 
By substituting eqn (9) into eqn (6) and making use of the ideal gas law relationship $\left(\frac{T-T_{0}}{T_{0}}=\frac{\left(\rho_{0}-\rho\right)}{\rho}\right)$ we obtain:

$T-T_{0}=\Delta T=\left(\frac{T_{0}}{\left(4 \alpha \rho_{0} C_{p}\right)^{2} g}\right)^{1 / 3}\left(\frac{Q_{c}}{w}\right)^{2 / 3} \frac{1}{z}$

The functional relationship for the in-rack velocity and in-rack temperature can now be used to plot the experimental data.

\section{EXPERIMENTS}

A series of model scale tests was carried out followed by one full scale test. The fuel array consisted of four equally separated cartons at each tier. The commodity was piled up to four levels, or tiers, with equal heights of the horizontal flues between every consecutive tiers. Geometrically, the commodity used in the model scale was approximately $1 / 3$ of the full scale commodity. Both commodities were made of combined corrugated paper cartons and paper sheets and differed only in type and size.

Model scale test: The experiments were carried out under a calorimeter consisting of an exhaust duct and a hood which is located above the fire [13]. The calorimeter had the capacity to measure up to about $2 \mathrm{MW}$. The hood size was $3 \mathrm{~m} \mathrm{x} 3 \mathrm{~m}$ with the lowest point $2.5 \mathrm{~m}$ from floor. Both the convective and chemical heat release rates were measured. The convective heat release rate was obtained by measuring the temperature and mass flow rate in the exhaust duct and the chemical heat release rate by measuring the oxygen depletion at the same location. The commodity consisted of $3.7 \mathrm{~mm}$ thick single wall corrugated paper cartons folded inside with four layers of $6.5 \mathrm{~mm}$ thick single wall corrugated paper sheets on each side of the carton. The total thickness of each side was thus $29.7 \mathrm{~mm}$. The sheets and the paper carton were mounted on a supporting rectangular box made of $9 \mathrm{~mm}$ thick rigid Navilite insulation boards. The outer dimensions of each carton were $0.39 \mathrm{~m} \mathrm{x} 0.39 \mathrm{~m}$ with a height of $0.305 \mathrm{~m}$ and the moisture content was $9 \%$ by weight. A total of 16 cartons were used in each test. Four separated vertical steel rods were used to support the cartons. On each steel rod four cartons were centrally mounted and secured in position. Cone Calorimeter [13] results of the material used are presented in [14]. The average value of the effective heat of combustion $\Delta H_{c}$ was $13.35 \mathrm{MJ} / \mathrm{kg}$. For comparison, Tewarson [15] has presented a value of $\Delta H_{c}=14.2 \mathrm{MJ} / \mathrm{kg}$ for corrugated paper cartons arranged in three dimensional, one or two tier rack storage. The time to ignition was measured in the cone calorimeter at irradiance of $25 \mathrm{~kW} / \mathrm{m}^{2}$ and $35 \mathrm{~kW} / \mathrm{m}^{2}$. The measured ignition times were 20 seconds and 9 seconds, respectively.

The vertical flue width, $w$, was varied as follows: $w=50 \mathrm{~mm}, 75 \mathrm{~mm}$ and $100 \mathrm{~mm}$. For $w=50$ $\mathrm{mm}$ the height, $h$, of the horizontal flue was varied as follows: $h=50 \mathrm{~mm}, 75 \mathrm{~mm}$ and $100 \mathrm{~mm}$. For $w=75 \mathrm{~mm}$ and $100 \mathrm{~mm} h$ was kept constant at $50 \mathrm{~mm}$. The total stack height $H$ varied depending on $h: H=1.42 \mathrm{~m}$ for $\mathrm{h}=50 \mathrm{~mm}, 1.52 \mathrm{~m}$ for $\mathrm{h}=75 \mathrm{~m}$ and $1.62 \mathrm{~m}$ for $h=100 \mathrm{~mm}$. One test was carried out by blocking the lowest horizontal flue ( $w=50 \mathrm{~mm}$ and $h=50 \mathrm{~mm})$.

At the lowest tier, four ignition sources were symmetrically mounted at the bottom of each carton as close as possible to centre flue space of the fuel array. The ignition source consisted of a $12 \mathrm{~mm}$ thick insulating fibre board measuring $17 \mathrm{~mm} \mathrm{x} 17 \mathrm{~mm}$, soaked with $2.8 \mathrm{ml}$ heptane and wrapped in a polyethylene bag. The mean flame height of the ignition source was about $0.25 \mathrm{~m}$ measured from the bottom of the carton. This height corresponds to $83 \%$ of the carton height. One test was carried out with a $24 \mathrm{~mm}$ thick ignition source measuring $25 \mathrm{~mm} \times 30 \mathrm{~mm}$, soaked with $12 \mathrm{ml}$ heptane $(w=50 \mathrm{~mm}$ and $h=50 \mathrm{~mm})$. 
Centreline in-rack temperatures and velocities were measured at four elevations: for $h=50 \mathrm{~mm}$ measurements were made at $z=0.25 \mathrm{~m}, 0.61 \mathrm{~m}, 0.96 \mathrm{~m}$ and $1.32 \mathrm{~m}$; for $h=75 \mathrm{~m}: z=0.28 \mathrm{~m}$, $0.66 \mathrm{~m}, 1.04 \mathrm{~m}$ and $1.42 \mathrm{~m}$; and for $h=100 \mathrm{~mm}: z=0.3 \mathrm{~m}, 0.71 \mathrm{~m}, 1.11 \mathrm{~m}$ and $1.52 \mathrm{~m}$. Each of these positions corresponds to $2 / 3$ of the height of the carton. The velocity probes were mounted in a staggered form (at the centreline and $+/-45 \mathrm{~mm}$ from the centreline) to avoid interference in these measurements. The ambient temperature varied between $13-15^{\circ} \mathrm{C}$ during the test series.

The full scale test: One full scale experiment was carried out under the Industry Calorimeter $[17,18]$ in SP's Fire Hall. The calorimeter, which is of same type as the FMRC Fire Products Collector [19], can measure up to $10 \mathrm{MW}$. Both the convective and the chemical heat release rates were measured. A Standard Class II commodity was used which consists of double triwall corrugated paper cartons (each $12 \mathrm{~mm}$ thick). The double cartons were folded onto a sheet-metal liner and then placed onto a wood pallet. The outer dimensions of each carton were $1.08 \mathrm{~m} \mathrm{x}$ $1.08 \mathrm{~m} \mathrm{x} 1.08 \mathrm{~m}$ and the moisture content was $11 \%$ by weight. A Cone calorimeter test was carried out with irradiance of $25 \mathrm{~kW} / \mathrm{m}^{2}$. The average value of $\Delta H_{c}$ was $11.5 \mathrm{MJ} / \mathrm{kg}$ and the time to ignition 34 seconds. Yu and Kung [6] determined the effective convective heat of combustion using Class II cartons in 4 tiers to be $6.1 \mathrm{MJ} / \mathrm{kg}$. Using an average value of the measured ratio of convective heat release rate to chemical heat release rate during the growing fire period of the full scale test performed here: $Q_{c} d Q=0.517$ for $38<Q_{c}<2000 \mathrm{~kW}$, we find that $\Delta H_{c}$ for Class II cartons is $11.8 \mathrm{MJ} / \mathrm{kg}$ which is in remarkably good agreement with the measured cone calorimeter value of $\Delta H_{c}=11.5 \mathrm{MJ} / \mathrm{kg}$.

A double-row steel rack was used to hold the commodity. The width of the vertical flues was $150 \mathrm{~mm}$ and the height of the horizontal flues was $300 \mathrm{~mm}$. The total height of the rack storage was $5.52 \mathrm{~m}$. Four ignition sources were symmetrically placed as close as possible to the centre flue space of the fuel array, at the bottom of each carton at the lowest tier. The ignition source consisted of insulating fibre board (similar to cellucotton rolls), $75 \mathrm{~mm}$ in diameter and $75 \mathrm{~mm}$ long, each soaked with $120 \mathrm{ml}$ heptane and wrapped in a polyethylene bag. The mean flame height of the ignition source was about $0.9 \mathrm{~m}$ measured from the bottom of the carton. This height corresponded to $83 \%$ of the carton height. Centreline in-rack temperatures and velocities were measured at four elevations: $z=1.02 \mathrm{~m}, 2.40 \mathrm{~m}, 3.78 \mathrm{~m}$ and $5.16 \mathrm{~m}$. Each of these positions corresponds to $2 / 3$ of the height of the carton. The ambient temperature was $11{ }^{\circ} \mathrm{C}$ during the test.

Instruments: The in-rack temperatures were measured with welded thermocouples of type $\mathrm{K}$ (Chromel-Alumel) with a wire diameter of $0.25 \mathrm{~mm}$. The in-rack velocity was measured with bi-directional probes $(D=16 \mathrm{~mm}$ and $L=32 \mathrm{~mm})$ [16] located at same elevation as the thermocouples. The thermocouples were attached to each bi-directional probes close to the sensor head. No correction due to radiation effects on the temperature measurements was carried out in this study. The velocity was corrected for variation in the Reynolds number according to calibration curves reported in [16]. A more thorough description of the test set-up is given in [14]. The data was recorded by a data acquisition system every second in the full scale test and every 1.7 seconds in the small scale tests.

\section{DATA ANALYSIS AND RESULTS}

In this study, only the initial fire growth period is considered. This period is defined here as the time from ignition until the flames starts to spread upwards on the face of the rack storage. Following the procedure of Yu and Kung [6] for growing rack storage fires, a rolling timeaveraging process was applied to all temperature, velocity and heat release rate measurements in order to smooth out fluctuations due to turbulence. The averaging period was 10 seconds. Thus each measurement was averaged using different numbers of data points before and after the 
point of interest. The time averaged results followed the trends of the unprocessed data very well.

All data points measured prior to the incipient time of fire growth, $t_{0}$, were disregarded in the data analysis and in plot of the data. The time $t_{0}$ was defined here as the time when the convective heat release rate started to increase notably in size. This time was obtained by investigating the measured convective heat release rates and by observing the initial flame heights from video recordings. The time $t_{0}$ agreed well with the time when the mean flame height of the ignition source just started to increase in size.

Fire growth rate: Yu and Stavrianidis [5] found that the convective heat release rate correlates with a power-law dependence on time to the third power for rack storage fires. This function worked well for the initial fire growth rate period, i.e., convective heat release rates up to 800 $\mathrm{kW}$ per tier which corresponds to $3200 \mathrm{~kW}$ for the 4 tier full scale test presented here. After studying a number of full scale tests, Thomas [4] described the fire growth rate of rack storage fires with line ignition by an exponential function, $Q \propto e^{3 t / 2 \tau}$, where $\tau$ equal to $10-15$ seconds was found plausible.

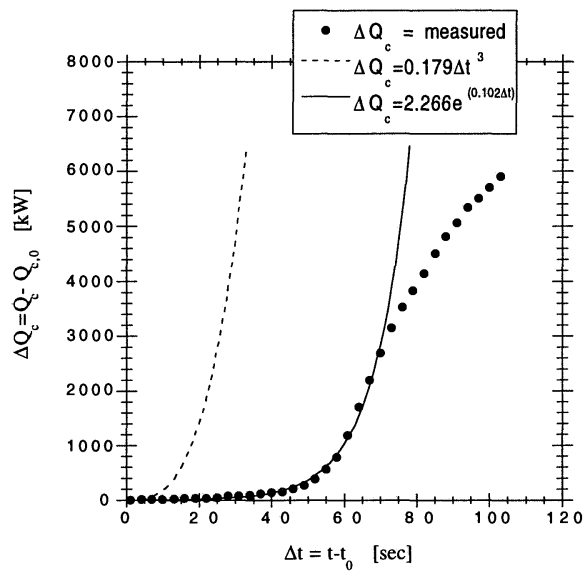

FIGURE 2. Comparison between measured net convective heat release rate and data fits using power law correlation [6] and an exponential correlation [4].

In figure 2, comparison of the measured net convective heat release rate, $\Delta Q_{c}=$ $Q_{c}-Q_{c, 0}$, is made with heat release rate correlations given in ref. [4] and [5]. $Q_{c, 0}$ is the convective heat release rate at $\mathrm{t}_{0}$. The measured $\Delta \mathrm{Q}_{\mathrm{c}}$ is shown as a function of the time, $\Delta t=t-t_{0}$. The fire growth rate coefficient in $\mathrm{Yu}$ and Stavriandidis [5] correlation for 4 tier high rack storage is 0.179 and thus the net convective heat release rate $\Delta Q_{c}=0.179 \Delta t^{3}$. An exponential curve fit was made to the measured net convective heat release rate in the full scale test; $\Delta Q_{c}=2.27 e^{(0.102 \Delta t)}$. This correlation follows the measured $\Delta Q_{c}$ remarkably well up to about $3000 \mathrm{~kW}$. Yu's and Stavriandidis [5] correlation follows the slope of the measured $\Delta Q_{c}$ very well but the initial time appears to be quite different. This is probably due to differences in the determination of $t_{0}$. However, since we are primary interested in the in-rack fire plume flow in order to predict the activation time of in-rack sprinklers, we need a correlation which describes 
the fire growth rate from the time the flames start to accelerate upward from the ignition source. An interesting observation is that $\tau$ here is found to be $3 /(2 * 0.102)=14.7$ seconds which is in good agreement with Thomas [4] prediction of $\tau$ equal to $10-15$ seconds.

The measured convective heat release rates, $Q_{c}$, for both small scale and full scale tests are plotted in figure 3. Apparently there is a turning point in the fire growth rate at $Q_{c} \approx 200 \mathrm{~kW}$ in the model scale tests. For $Q_{c}<200 \mathrm{~kW}$, increase of the vertical flue width $w$ tends to delay the fire growth rate whereas variation of the horizontal flue height $h$ appear to affect the fire growth rate slightly. However, for $Q_{c}>200 \mathrm{~kW}$, smaller $w$ tends to retard the fire growth rate whereas larger $h$ tends to proceed with a similar fire growth rate. In general, a large $w$ and a small $h$ appears to give slower initial fire growth rates and flame spread rates.

A test with $w=50 \mathrm{~mm}$ and $h=50 \mathrm{~mm}$ using large ignition source and a test with same dimensions using a blockage at the lowest horizontal flue, were also carried out. The large ignition source influenced the initial fire growth rate considerably (faster initial fire growth) but it did not affect the slope of the curve. A blockage of the lowest horizontal flue did not have any affects on the fire growth rate. To investigate the reproducibility, two replicates with $w=75 \mathrm{~mm}$ and $h=50 \mathrm{~mm}$ were performed. The results were found to be nearly identical.

Estimations of times from video recordings of flame spread are presented in Table 1. Apparently the incipient time, $t_{0}$, is directly related to variation in $w$. Clearly $h$ influence the average vertical luminous flame height speed, $u_{f}$, considerably. Further, in figure 3 , it was observed that $Q_{c}$ was slightly affected by variation in $h$. The average upward flame speed, $u_{f}$, in the full scale test agree with the upward flame speed derived by Thomas [4], i.e., $u_{f}=0.1 \mathrm{~m} / \mathrm{s}$. Thomas [4] value is based on a number of full scale tests. It is evident from the model scale tests, however, that $u_{f}$ varies considerably with $w$ and $h$. There is some inconsistency in the data in Table 1 . The behavior of the fire growth rate with $h$ and the observed flame height appear inconsistent. Furthermore, Figure 3 shows that the fire with $h=100 \mathrm{~mm}$ develops slightly slower than the fires with $h=50 \mathrm{~mm}$ and $75 \mathrm{~mm}$. Further analysis of the data is necessary.

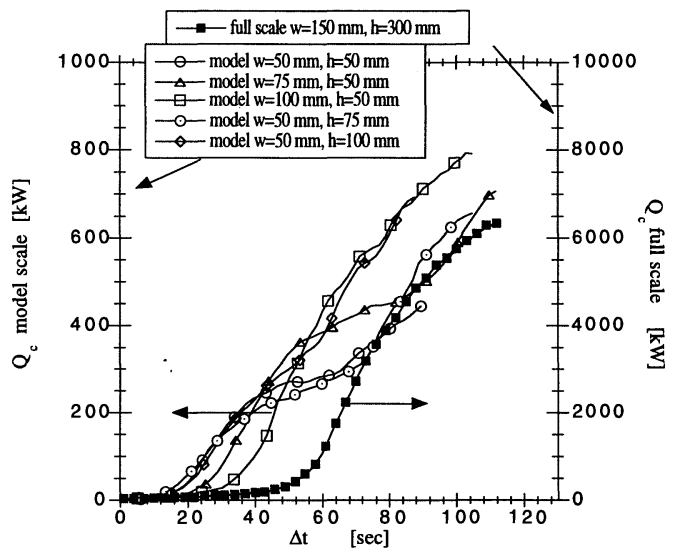

FIGURE 3. Convective heat release rate in the model scale tests (left y-axis) and the full scale test (right y-axis). 
TABLE 1. In-rack flame spread where $t=$ time from ignition, $t_{0}=$ incipient time of fire growth, $t f=$ time from ignition for average flame tip to reach the top of the storage, uf is the mean in-rack flame speed, th=time from to for horizontal flue flames to reach the face of the rack, $t_{E}=$ time from to where the outer face of the rack is engulfed with flames at tier two, three and four.

\begin{tabular}{|l|c|c|c|l|l|l|c|}
\hline Experiment & $\begin{array}{l}\mathrm{t}_{0} \\
(\mathrm{~s})\end{array}$ & $\begin{array}{l}\mathrm{t}_{\mathrm{f}} \\
(\mathrm{s})\end{array}$ & $\begin{array}{l}\Delta \mathrm{t}_{\mathrm{f}}=\mathrm{t}_{\mathrm{f}}-\mathrm{t}_{0} \\
(\mathrm{~s})\end{array}$ & $\begin{array}{l}\mathrm{u}_{\mathrm{f}} \\
(\mathrm{m} / \mathrm{s})\end{array}$ & $\begin{array}{l}\mathrm{t}_{\mathrm{h}} \\
(\mathrm{s})\end{array}$ & $\begin{array}{l}\mathrm{t}_{\mathrm{E}} \\
(\mathrm{s})\end{array}$ & $\begin{array}{l}\Delta \mathrm{tE}_{\mathrm{E}}=\mathrm{t}_{\mathrm{E}}-\mathrm{t}_{\mathrm{h}} \\
(\mathrm{s})\end{array}$ \\
\hline model $w=50 \mathrm{~mm}, h=50 \mathrm{~mm}$ & 13.0 & 30 & 17 & 0.084 & 29.0 & 77.0 & 48 \\
\hline model $w=75 \mathrm{~mm}, h=50 \mathrm{~mm}$ & 22.6 & 45 & 22.4 & 0.063 & 31.4 & 81.4 & 50 \\
\hline model $w=100 \mathrm{~mm}, h=50 \mathrm{~mm}$ & 26.3 & 55 & 28.7 & 0.050 & 33.7 & 93.7 & 60 \\
\hline model $w=50 \mathrm{~mm}, h=75 \mathrm{~mm}$ & 19.6 & 32 & 12.4 & 0.123 & 29.4 & 76.4 & 47 \\
\hline model $w=50 \mathrm{~mm}, h=100 \mathrm{~mm}$ & 17.4 & 30 & 12.6 & 0.129 & 22.6 & 53.6 & 31 \\
\hline full scale test $w=150, h=300$ & 40 & 95 & 55 & 0.100 & 45.0 & 95.0 & 50 \\
\hline
\end{tabular}

As the flames spread upwards, they start to spread horizontally through the lateral flues. The time for the flames to reach to the face of the rack storage, $t_{h}$, is given in Table 1 . It is apparent that the lateral flame spread is dependent on variation in $w$. It takes longer timer to reach to the face of the rack storage with increasing $w$. However, an increase in $h$ appears to shorten this time. The flames usually reached first to the rack storage face in the flue between tiers 3 and 4 in the model scale tests whereas for the full scale test this occurred between tiers 2 and 3 . Finally, times until the rack storage is entirely engulfed with flames on the outside are given. Apparently it too follows the trend of $t_{h}$.

Centreline in-rack temperature: To investigate the validity of the theoretical obtained correlations, the experimental data at tiers 2,3 and 4 have been plotted on a log-log graph. The experimental data obtained at the lowest tier was disregarded here as it did not fit very well to the obtained correlation. The reason for this is probably that the combustion zone is initially at the lowest tier and the plume flow and $Q_{c}$ are not fully developed at this height. This behaviour was observed in the $2 \mathrm{D}$ rack storage presented in ref. [2]. Based on eqn (10) the in-rack temperature should correlate as:

$\Delta T \propto\left(\frac{Q_{c}}{w}\right)^{2 / 3} \frac{1}{z}$

In the log-log graph, the data fall into a single curve for both scales but there is some scatter in the data. By introducing a virtual source height, $z_{0}$, preliminary calculations show that a plot of $\Delta T$ as a function of $\left(z-z_{0}\right)^{3 / 2} /\left(Q_{d} / w\right)$ in a log-log graph will fall onto a line with a slope of $-2 / 3$. The preliminary calculations indicate that $z_{0}$ is usually above the floor level and increase in height with increasing $Q_{c}$.

Centreline in-rack velocity: Based on eqn (8) the measured in-rack velocity at tiers 2, 3 and 4 has been plotted according to the following relationship:

$u \propto\left(\frac{Q_{c}}{w}\right)^{1 / 3}$ 


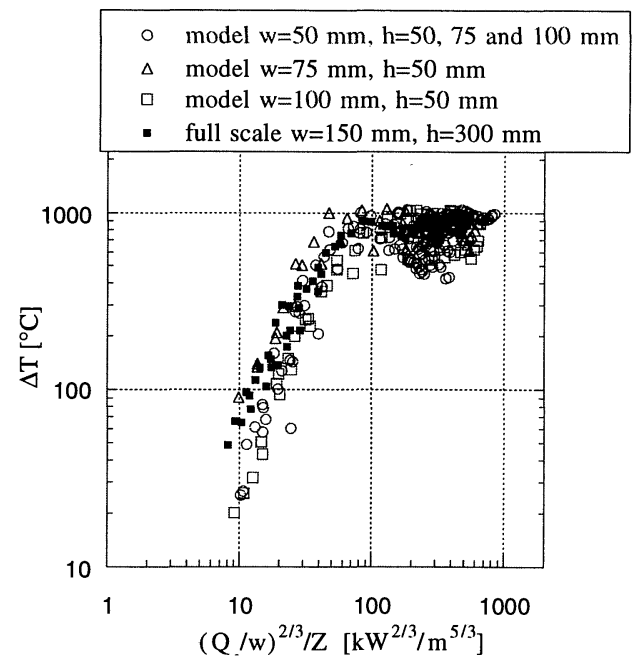

FIGURE 4. Excess in-rack temperature plotted as a function of $\left(Q_{c} / w\right)^{2 / 3 / z}$ at tiers 2,3 and 4 .

In order to obtain similar correspondance for the velocity in the two scales it was necessary to use Froude number scaling with storage height, $H$, as a length scale. This does not comply with the results of a line plume model which indicates constant velocity independent of height $z$. Thus, there appears to be a height dependence of the velocity which in turn indicate that there may be other sets of correlations which could be used to plot the data (e.g. axisymmetric correlations).

Here we define the Froude number as:

$$
\left(F r=\frac{u^{2} T_{0}}{g H \Delta T}\right)
$$

Using eqns (11) - (13) we obtain:

$$
\frac{u}{\sqrt{H}} \propto \frac{\left(\frac{Q_{c}}{w}\right)^{1 / 3}}{\sqrt{H}}
$$

In the log-log graph, the data fall into a single curve for both scales but the scatter in the data is considerable. The experimental data obtained at the first tier did not fit to the obtained correlation. 


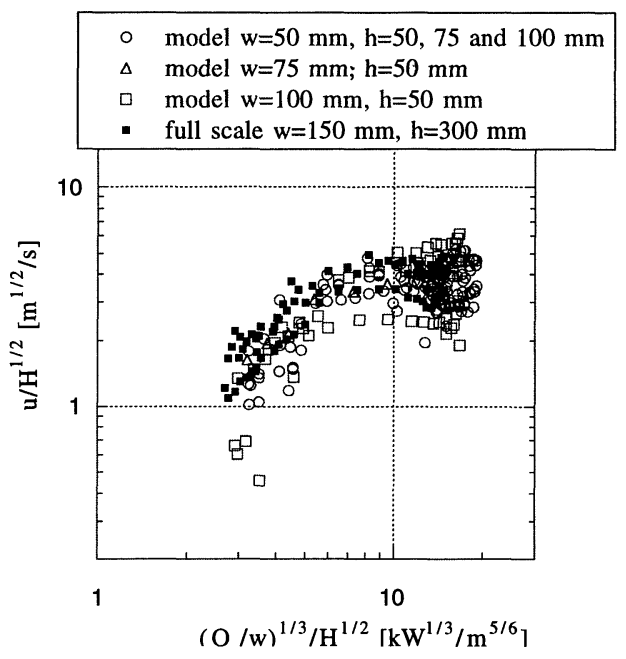

FIGURE 5. In-rack centreline velocity plotted as a function of $\left(Q_{c} / w\right)^{1 / 3} / H^{1 / 2}$ at tiers 2,3 and 4 .

\section{CONCLUSIONS}

A theoretical and experimental study of in-rack fire plumes in a combustible rack storage is presented. Free-burn tests were carried out mostly in reduced scale with verification in full scale. The centreline in-rack gas temperatures and velocities were measured at four elevations inside the rack storage. In-rack temperatures and velocities are plotted using theoretically obtained quasi-steady correlations assuming a point source of buoyancy at floor level and entrainment only in the vertical flues. The theoretical correlations include convective heat release rate, vertical flue width and height above floor. Temperatures and velocities for both reduced scale and full scale correlate reasonably well with the theoretically obtained relationships which have the same functional form as convective plume flow above a linear fire source. In order to obtain similar correspondance for the velocity in the two scales it was necessary to use Froude number scaling with storage height as length scale. This does not comply with the results of a linear plume model which indicates constant velocity independent of elevation height.

For the initial in-rack fire growth rate, the convective heat release rate was found to be better described by an exponential rather than power-law dependence on time to third power. The reduced scale study shows that the initial fire growth rate is decreased when vertical gaps (flues) increase in size. Furthermore, for a given vertical gap size both the vertical and lateral flame spread rate increase when the lateral flue height increases. Despite the complexity of rack storage fires, a way to provide necessary flow data to calculate response times of in-rack sprinklers is demonstrated. The model can be easily extended to include flame heights correlations as well.

\section{ACKNOWLEDGEMENT}

The sponsorship of the Swedish Fire Research Board (BRANDFORSK) is gratefully acknowledged. Special thanks to Drs Bror Persson and Margaret Simonson at SP for their valuable comments and helpful discussion. 


\section{REFERENCES}

1. Ingason, H., Two Dimensional Rack Storage Fires, Fire Safety Science, Proceedings of the 4th International Symposium, pp. 1209-1220.

2. Ingason, H., Modelling of Two Dimensional Rack Storage Fires, Swedish National Testing and Research Institute, SP-Report 1993:57.

3. Foley, M., and Drysdale, D.D., Heat Transfer from Flames between Vertical Parallel Walls, Fire Safety Journal, 24, (1995), p. 53-73.

4. Thomas, P.H., Some Comments on Fire Spread in High Racked Storage of Goods, Department of Fire Safety Engineering, Lund University, 1993.

5. Yu, H-Z. and Stavrianidis, P., The Transient Ceiling Flows of Growing Rack Storage Fires, Fire Safety Science-Proceedings of the Third International Symposium, pp. 281290.

6. $\mathrm{Yu}, \mathrm{H}-\mathrm{Z}$., and Kung, H-C., Strong Buoyant Plumes of Growing Rack Storage Fires, The Twentieth Symposium (International) on Combustion, P. 1567, The Combustion Institute, 1984.

7. Kung, H-C., Yu, H-Z, and Spaulding, R.D., Ceiling Flows of Growing Rack Storage Fires, Twenty-First Symposium (International) on Combustion, The Combustion Institute, PP. 121-128, 1986.

8. Field, P., Effective Sprinkler Protection for High Racked Storage, Fire Surveyor, October 1985.

9. NFPA 231C, vol. 6, National Fire Protection Association, Batterymarch Park, Quincy, MA 02269-9101.

10. The Protection of High Piled Storage with Sprinklers, FIRTO Technical Evaluation Report, TE2187, F.I.R.T.O. Borehamwood, 1984.

11. Person, H., Evaluation of the RDD-measuring Technique, RDD-tests of the CEA and FMRC standard plastic commodities, Swedish National Testing and Research Institute, SP-Report 1991:04

12. Lee, S-L and Emmons, H.W., A Study of Natural Convection above a Line Fire, Journal of Fluid Mechanics, Vol. 11, part 3, p. 353-369.

13. Babrauskas, V., and Grayson, S., Heat Release in Fires, Elsevier Applied Science, 1992.

14. Ingason, H., In-Rack Plumes of Growing Rack Storage Fires, Swedish National Testing and Research Institute, To be published.

15. Tewarson, A., Generation of Heat and Chemical Compounds in Fires, The SFPE Handbook of Fire Protection Engineering, 2nd Edition, p.3-53 to 3-124, National Fire Protection Association, Society of Fire Protection Engineers, 1995.

16. McCaffrey, B.J. and Heskestad, G., A Robust Bi-directional Low-Velocity Probe for Flame and Fire Application, Combustion and Flame, 26, 125-127, 1976.

17. Dahlberg, M., The SP Industry Calorimeter, For rate of heat release rate measurements up to $10 \mathrm{MW}$, SP Report 1992:43.

18. Dahlberg, M., Error Analysis for Heat Release Rate Measurement with the SP Industry Calorimeter, SP Report 1994:29.

19. Heskestad, G., A Fire Products Collector for Calorimetry into the MW Range, Report FMRC J.I. OC2E1.RA, Factory Mutual Research Corporation, Norwood. 